\title{
ANALISIS SISTEM ANTRIAN DI DINAS KEPENDUDUKAN DAN PENCATATAN SIPIL KABUPATEN SIGI (Studi Pada Pelayanan Pencatatan dan Penerbitan Kartu Tanda Penduduk)
}

\author{
Satriani \\ Asngadi \\ Program Studi S1 Manajamen, Fakultas Ekonomi dan Bisnis, Universitas Tadulako \\ Email: satriani6nitong@gmail.com \\ Abstract
}

This research aims to analyze the optimal service queue system in making the identity card (KTP) in the Office of the Population and civil registration of Sigi District. The method of analysis used is $M / M / 1$ and $M / M / S$. The results of the analysis by using one counter in cated that the utility level data collection phase is 1.13 or $113 \%$, the recording stage is 0.9 or $90 \%$ and the printing stage is 3 or $300 \%$. While the addition of the counters, the utility counters can be reduced to 0.57 or $57 \%$ where average number of in the system is 2 people, the recording stage is 0.45 or $45 \%$ where number of person in the system is 1 person and the printing stage is 0.75 or $75 \%$ with the average people in the system is 5 people. This indicates that by adding a counter to each level, can optimize service on The National identity Card (KTP), the Department of Population and Civil registration of Sigi District.

Keywords: System Queuing, Optimal.

\begin{abstract}
Abstrak
Penelitian ini bertujuan untuk menganalisis sistem antrian pelayanan yang optimal pada loket pembuatan Kartu Tanda Penduduk (KTP) yang ada di Dinas Kependudukan dan Pencatatan Sipil Kabupaten Sigi. Metode analisis yang digunakan adalah M/M/1 dan M/M/S. Hasil analisis dengan menggunakan satu loket pada setiap tahapnya dengan tingkat utilitas yaitu tahap pendataan adalah 1,13 atau $113 \%$, tahap perekaman adalah 0,9 atau $90 \%$ dan tahap pencetakan adalah 3 atau 300\%. Sedangkan dengan melakukan penambahan loket pada setiap tahapnya tingkat utilitas loket dapat berkurang menjadi 0,57 atau 57\% dengan jumlah masyarakat rata-rata dalam sistem adalah 2 orang, tahap perekaman adalah 0,45 atau $45 \%$ dengan jumlah masyarakat rata-rata dalam sistem adalah 1 orang dan tahap pencetakan adalah 0,75 atau $75 \%$ dengan jumlah masyarakat rata-rata dalam sistem adalah 5 orang, hal ini menunjukkan bahwa dengan melakukan penambahan loket pada setiap tahapnya dapat mengoptimalkan pelayanan pada loket pembuatan Kartu Tanda Penduduk (KTP) yang ada di Dinas Kependudukan dan Pencatatan Sipil Kabupaten Sigi.
\end{abstract}

Kata Kunci: Sistem Antrian, Optimal.

\section{PENDAHULUAN}

Sistem antrian merupakan keseluruhan dari proses para masyarakat atau barang yang berdatangan yang memasuki barisan antrian yang seterusnya memerlukan pelayanan sebagaimana seharusnya berlaku. Dalam mempelajari suatu sistem antrian, perlu diketahui bahwa susunan garis tahap layanan antrian, yaitu yang memerlukan layanan disebut masyarakat (customer) dan yang melayani disebut pelayanan (serve). (Pardede dkk., 2014).

Dinas Kependudukan dan Pencatatan Sipil Kabupaten sigi adalah salah satu kantor pelayanan umum yang memberikan pelayanan umum terhadap masyarakat yang ada di Kabupaten Sigi. Ada beberapa jenis pelayanan yang di berikan oleh kantor tersebut dan salah satunya adalah pelayanan pencatatan dan penerbitan Kartu Tanda Penduduk. Kebutuhan akan pelayanan ini lebih tinggi dibandingkan dengan kebutuhan pelayanan lain yang tersedia di Dinas Kependudukan dan Pencatatan Sipil Kabupaten Sigi. Tingginya tingkat kedatangan mengakibatkan panjangnya antrian sehingga menyebabkan waktu tunggu yang dialami oleh masyarakat juga cukup lama, dan antrian yang cukup lama menjadi salah satu penyebab ketidakpuasan masyarakat terhadap pelayanan yang diberikan. 


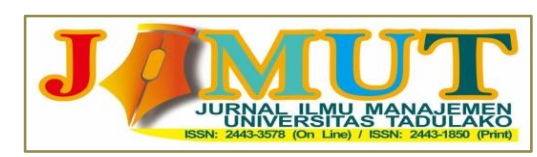

Vol. 6, No.2, Mei 2020, 112-120

Sistem antrian yang diterapkan oleh Dinas Kependudukan Dan Pencatatan Sipil Kabupaten Sigi pada loket pelayanan pencatatan dan penerbitan Kartu Tanda Penduduk adalah sistem antrian Single Channel Multiple Phase. Setelah menerima pelayanan tahap pertama, masyarakat menuju tempat pelayanan kedua sebagai pelengkap pelayanan pertama dan seterusnya hingga pelayanan menjadi sempurna. Setelah pelayanan yang diberikan sempurna, masyarakat dapat meninggalkan area pelayanan atau keluar dari sistem.

\section{KAJIAN LITERATUR}

\section{Landasan Teori}

Manajemen Operasional merupakan suatu bentuk pengaturan untuk masalah produksi dan operasional yang mencakup bidang barang dan jasa. Handoko (2010:3) mengartikan bahwa manajemen produksi dan manajemen operasi adalah suatu usaha pengelolaan atau pengerjaan secara optimal dalam penggunaan sumber daya (disebut faktor produksi) tenaga kerja, mesin-mesin, peralatan, bahan setengah mentah dan bahan mentah sebagainya dalam proses transformasi menjadi produk yang siap untuk dipasarkan.

Siagian (1987) mengartikan antrian sebagaai suatu garis tunggu masyarakat yang ingin mendapatkan pelayanan dari suatu fasilitas pelayanan. Sedangkan dari pendapat Haizer dan Rendeer (2008), antrian merupakan barang ataupun manusia yang sedang menunggu untuk dilayani.

Menurut Haizer dan Render (2006: 659) ada tiga komponen disebuah system antrian adalah: (1) kedatangan atau memasukkan sistem, (2) antrian itu sendiri atau disiplin dalam antrian, dan (3) fasilitas layanan. Ketiga komponen tersebut memiliki beberapa karakteristik tersendiri yang disebut karakteristik kedatangan, karakteristik antrian dan karakteristik pelayanan.

\section{Struktur Antrian}

\section{Satu Antrian Satu pelayanan (Single Channel Single Phase)}

Struktur antrian ini merupakan struktur antrian yang sangat mudah. Single channel menunjukan jalur yang digunakan untuk memasuki system layanan hanya ada satu jalur saja. Contoh: penerapan struktur ini adalah pengisian bahan bakar pada SPBU, pembelian tiket yang dilayani oleh satu loket, dan lain-lain.

\section{Satu Antrian Beberapa Pelayanan Tunggal (Multiple Channel Single Phase)}

Struktur tersebut mempunyai jalur berganda atau lebih dari satu layanan sedangkan sistem layanan hanya satu fase. Contoh: masyarakat bank yang menunggu untuk mendapat layanan loket.

\section{Beberapa Antrian Beberapa Pelayanan Paralel (Multi Channel-Multiphase)}

Pada sistem ini memiliki banyak fasilitas layanan disetiap tahapannya, sehinga bisa melayani lebih banyak masyarakat dalam waktu yang sama. Contohnya : melayani pasien di rumah sakit, perawat akan bergantian melayani pasien, mulai dari tahap pertama atau pendaftaran, pemeriksaan, perawatan hingga pasien dinyatakan sehat. 


\section{Satu Antrian beberapa Pelayanan Paralel (Single Channel Multiple Phase)}

Pelayanan yang dilakukan secara bertahap mulai dari tahap pertama lalu yang kedua sehingga pelayanan menjadi lengkap dan sampai seterusnya. Sesudah layanan yang di berikan sempurna maka masyarakat dapat keluar dari system. Contoh sistem pelayanan dengan struktur ini adalah pembuatan Surat Izin Mengemudi (SIM).

\section{Hubungan antara Pengalaman Konsumen dengan Loyalitas}

Tiap perusahaan memiliki suatu cara dalam menciptakan sebuah strategi untuk menarik konsmen bukan hanya sekedar berkunjung akan tetapi bagaimana cara perusahaan tersebut menciptakan sesuatu hal yang membekas baik dibenak konsumen. Mempertahankan konsumen agar tetap loyal dibutuhkan strategi yang tidak hanya memfokuskan pada kualitas tetapi juga bisa menciptakan pengalaman konsumen yang baik. Pengalaman yang terbentuk dalam diri konsumen menjadi faktor penentu yang signifikan terhadap berkunjungnya kembali konsumen pada perusahaan tersebut.

Ehret (2008) mengembangkan model yang menghubungkan antara pengalaman konsumen, loyalitas dan word of mouth. Pengalaman konsumen yang baik akan menghasilkan loyalitas dan word of mouth, dimana loyalitas tetap menjaga konsumen, sedangkan word of mouth akan berguna dalam ekspansi dan akuisi pelanggan baru.

Pada dasarnya pengalaman konsumen adalah penciptaan kepuasan konsumen terhadap pengalaman yang telah dia dapatkan dari suatu perusahaan. Jadi, titik bertumpu kepada produk akhir dari suatu produk atau pelayanan, oleh karena itu, pengalaman konsumen adalah soal memahami gaya hidup konsumen (mahasiswa) dan melebarkan pandangan pemasar dari produk ke proses konsumsi. Evaluasi pengalaman konsumen tergantung pada perbandingan antara harapan konsumen dan kinerja perusahaan. Apabila harapan konsumen dapat terpenuhi dengan baik tentunya konsumen akan merasa puas dan perlahan loyalitas konsumen pun akan terbentuk.

\section{Metode Penelitian}

\section{Jenis Penelitian}

Jenis pada penelitian ini termasuk penelitian dengan metode deskriptif - kuantitatif. Tujuan penelitian ini untuk menggambarkan sifat sesuatu yang tengah berlangsung pada saat penelitian dilakukan.

\section{Lokasi Penelitian}

Lokasi dalam penelitian ini adalah Dinas Kependudukan dan Pencatatan Sipil Kabupaten Sigi dijalan Trans Palu-Kulawi km. 11 Desa Kotarindau Kecamatan Dolo Kabupaten Sigi.

\section{Populasi}

Populasi yang digunakan adalah semua masyarakat pemula yang ingin menggunakan Kartu Tanda Penduduk dan mengantri pada loket pelayanan pencatatan dan penerbitan Kartu Tanda Penduduk pada Dinas Kependudukan dan Pencatatan Sipil Kabupaten Sigi.

\section{Teknik Penarikan Sampel}

Dalam penelitian ini penarikan sampel dari populasi dilakukan dengan mengacu pada metode pengambilan sampel sampling purposive. Sampling purposive adalah teknik penentuan sampel dengan 
pertimbangan tertentu Sugiyono (2014: 122). Pengumpulan sampel penelitian dilakukan selama satu bulan, yaitu dimulai pada pukul 08:00-12.00 dan 14.00-16:00 (jam kerja).

\section{Jenis dan Sumber Data}

\section{Data Kuantitatif}

Data ini merupakan data yang bisa di dapatkan dalam bentuk angka yang dapat di ketahui jumlahnya. Data kuantitatif yang digunakan data yang berupa kedatangannya per satuan waktu, dan data tingkat layanan rata- rata persatuan waktu.

\section{Data Kualitatif}

Data ini ialah data yang mempunyai ciri sistematik, narasi ataupun uraian yang tidak bisa di ketahui jumlahnya. Data ini dipakai pada penelitian ini seperti data hasil wawancara, keterangan mengenai gambaran umum perusahaaan dan keterangan lain yang berhubungan dengan antrian dan layanan di Dinas Kependuudukan dan Pencatatan Sipil Kabupaten Sigi.

\section{Sumber Data}

\section{Data Primer}

Pada penelitian ini data primer ialah data yang di dapatkan langsung dari pengamatan di tempat penelitian dan wawaancara dengan narasumber yang berkaitan dengan objek penelitian data kedatangan masyarakat, data tingkat layanan per satuan waktu dan data pelayanan di Dinas Kependudukan dan Pencatatan Sipil.

\section{Data Sekunder}

Data sekunder pada penelitian ini di dapatkan dari hasil studi pustaka dan mencari di literatur yang berkaitan dengan penelitian seperti penelitian- penelitian terdahulu dan hasil penelitian kepustakaan.

\section{Teknik Pengumpulan Data}

\section{Riset Lapangan}

1. Observasi, ialah meninjau dan mengevaluasi secara langsung bagian di Dinas Kependuduukan dan Penatatan Sipil Kab. Sigi yang berkaitan dengan masalah yang ingin di teliti. Teknik ini bermaksud untuk mengumpulkan data kedatangan masyarakat dan data tingkat pelayanan yang dicatat dalam lembar kerja.

2. Wawancara, ialah melakukan tanya jawab bersama pihak yang bersangkutan dengan perusahaan dan masalah yang di teliti. Penelitian memerlukan wawancara dengan pihak dari Dinas Kependudukan dan Pencataan Sipil Kabupaten Sigi mengenai standar antrian yang digunakan pada kantor tersebut.

\section{Riset Kepustakaan}

Pengumpulan data data dengan cara mempelajari dan membaca bahan- bahan yang berkaitan dengan masalah- masalah yang ingin di teliti agar dapat memberikan patokan yang di perlukan pada penelitian ini ialah mengenai jenis antrian. 


\section{Dokumentasi}

Dokumentasi ditujukan untuk memperoleh data langsung dari tempat penelitian, meliputi bukubuku yang relevan, peraturan-peraturan, laporan kegiatan, dan data yang nyata dari penelitian.

\section{Metode Analisis Data}

Dalam menganalisis data, peneliti menggunakan model antrian $\mathrm{M} / \mathrm{M} / 1$ yaitu model antrian dengan jalur tunggal dengan kedatangan berdistribusi poisson dan waktu pelayanan eksponensial dengan membandingkan penambahan loket dengan menggunakan model antrian M/M/S yaitu model jalur berganda atau lebih pelayanan untuk menangani masyarakat. Beberapa persamaan yang dapat diperhitungkan dalam mengukur kinerja suatu antrian yakni $\mathrm{L}_{\mathrm{s}}, \mathrm{W}_{\mathrm{s}}, \mathrm{L}_{\mathrm{q}}, \mathrm{W}_{\mathrm{q}}, \mathrm{P}, \mathrm{P}_{0}$, dan $\mathrm{P}_{\mathrm{n}>\mathrm{k}}$ sebagai berikut:

a. Model M/M/1

1. Jumlah rata-rata masyarakat dalam sistem:

$$
L_{s}=\frac{\lambda}{\mu-\lambda}
$$

2. Jumlah waktu rata-rata yang dihabiskan dalam sistem:

$$
W_{S}=\frac{1}{\mu-\lambda}
$$

3. Jumlah rata-rata masyarakat yang menunggu dalam antrian:

$$
L_{q}=\frac{\lambda^{2}}{\mu(\mu-\lambda)}
$$

4. Jumlah rata-rata waktu masyarakat menunggu dalam antrian:

$$
W_{q}=\frac{\lambda}{\mu(\mu-\lambda)}
$$

5. Faktor utilitas sistem:

$$
P=\frac{\lambda}{\mu}
$$

6. Probabilitas 0 masyarakat dam sistem:

$$
P_{0}=1-\frac{\lambda}{\mu}
$$

7. Probabilitas terdapat $\mathrm{k}$ masyarakat dalam sistem:

$$
P_{n>k}=\left(\frac{\lambda}{\mu}\right)^{k+1}
$$

b. Model M/M/S

1. Probabilitas 0 masyarakat dalam sistem:

$$
P_{0}=\frac{1}{\left[\sum_{n=0}^{M-1} \frac{1}{n !}\left(\frac{\lambda}{\mu}\right)^{n}\right]+\frac{1}{M !}\left(\frac{\lambda}{\mu}\right)^{M} \frac{M \mu}{M \mu-\lambda}}
$$


2. Tingkat utilitas loket:

$$
\rho=\frac{\lambda}{M \mu}
$$

3. Jumlah rata-rata masyarakat dalam sistem:

$$
L_{s}=\frac{\lambda \mu\left(\frac{\lambda}{\mu}\right)^{M}}{(M-1) !(M \mu-\lambda)^{2}} P_{0}+\frac{\chi}{\mu}
$$

4. Jumlah waktu rata-rata yang dihabiskan dalam sistem:

$$
W_{s}=\frac{L_{s}}{\chi}
$$

5. Jumlah rata-rata masyarakat yang mengunggu dalam antrian:

$$
L_{q}=L_{s}-\frac{\lambda}{\mu}
$$

6. Jumlah rata-rata waktu masyarakat menunggu dalam antrian:

$$
W_{q}=\frac{L_{q}}{\lambda}
$$

4. Hasil dan Pembahasan

Hasil Pengolahan Data

Tabel 1

Hasil Kinerja Sistem Antrian Loket Pembuatan Kartu Tanda Penduduk (KTP) Dengan Menggunakan 1 Jalur Antrian

\begin{tabular}{|c|c|c|c|c|c|c|c|}
\hline $\begin{array}{c}\text { Periode } \\
\text { Waktu }\end{array}$ & $\begin{array}{c}\mathbf{L}_{\mathbf{s}} \\
\text { (Orang) }\end{array}$ & $\begin{array}{c}\mathbf{W}_{\mathbf{s}} \\
(\text { Menit) }\end{array}$ & $\begin{array}{c}\mathbf{L}_{\mathbf{q}} \\
(\text { Orang) }\end{array}$ & $\begin{array}{c}\mathbf{W}_{\mathbf{q}} \\
(\text { Menit) }\end{array}$ & $\mathbf{P}(\boldsymbol{\%})$ & $\mathbf{P}_{\mathbf{0}}(\boldsymbol{\%})$ & $\boldsymbol{P}_{\boldsymbol{n} \mathbf{k}}$ \\
\hline $08.00-12.00$ & 0,75 & 0,0834 & 46,2858 & 5,1429 & 0,4286 & 0,5714 & 0,1837 \\
\hline $14.00-16.00$ & 4,5 & 0,5 & 14,7273 & 1,6364 & 0.8182 & 0,1819 & 0,6695 \\
\hline
\end{tabular}

Sumber: Dinas Kependudukan dan Pencatatan Sipil Kabupaten Sigi (Diolah Kembali)

Dilihat dari Tabel 1 di atas terlihat bahwa:

1. Jumlah rata-rata masyarakat dalam sistem $\left(\mathrm{L}_{\mathrm{s}}\right)$

Jumlah rata-rata masyarakat dalam sistem yang terbanyak terjadi pada periode waktu 14.00-16.00 yaitu sebanyak 4,5 atau dibulatkan menjadi 6 orang.

2. Jumlah rata-rata waktu yang dihabiskan masyarakat dalam sistem $\left(\mathrm{W}_{\mathrm{s}}\right)$

Waktu rata-rata yang dihabiskan masyarakat dalam sistem yang terlama terjadi pada periode waktu yaitu selama 0,5 menit.

3. Jumlah rata-rata masyarakat berada dalam antrian $\left(\mathrm{L}_{\mathrm{q}}\right)$

Jumlah rata-rata masyarakat yang terpanjang berada dalam antrian terjadi pada periode waktu 08.0012.00 yaitu 46,29 atau dibulatkan 47 orang. 
4. Jumlah rata-rata waktu yang dihabiskan masyarakat dalam antrian $\left(\mathrm{W}_{\mathrm{q}}\right)$

Waktu rata-rata yang dihabiskan masyarakat dalam antrian yang terlama terjadi pada 08.00-12.00 yaitu 5,15 .

5. Faktor utilisasi sistem $(P)$

Tingkat kesibukan loket terjadi pada periode waktu $14.00-16.00$ yaitu 0,82 atau $82 \%$.

6. Probabilitas tidak terdapat masyarakat dalam sistem $\left(P_{0}\right)$

Probabilitas tertinggi sistem kosong atau tidak ada masyarakat dalam sistem terjadi pada periode waktu 08.00-12.00 yaitu 0,58 atau 58\%.

7. Probablitas terdapat $\mathrm{k}$ masyarakat dalam sistem, dimana $\mathrm{n}$ adalah jumlah masyarakat dalam sistem $\left(P_{n>k}\right)$

Probablitas tertinggi terdapat masyarakat dalam sistem dimana $\mathrm{n}$ jumlah masyarakat dalam sistem, terjadi pada periode waktu 14.00-16.00 yaitu 0,67.

Dengan melihat jumlah di atas, jumlah loket yang diterapkan oleh Dinas Kependudukan dan Pencatatan Sipil Kabupaten Sigi belum optimal untuk melayani masyarakat, dengan melihat waktu rata-rata menunggu masyarakat dalam antrian adalah 5,15 menit, sedangkan banyak masyarakat dalam antrian yang terpanjang adalah 47 orang, dan melihat tingkat kesibukan loket (utilitas) yang terbanyak terjadi pada periode waktu 14.00-16.00 yaitu sebesar 0,82 atau 82\%, hal ini menandakan bahwa loket pembuatan Kartu Tanda Penduduk sangatlah sibuk dan belum dapat dikatakan optimal.

Tabel 2

Rata-Rata Hasil Kinerja Sistem Antrian Dinas Kependudukan dan Pencatatan Sipil Kabupaten Sigi Menggunakan M/M/1 dan M/M/S

\begin{tabular}{|c|c|c|c|c|c|c|c|}
\hline $\begin{array}{c}\text { Model } \\
\text { Antrian }\end{array}$ & $\begin{array}{c}\mathbf{L}_{\mathbf{s}} \\
\text { (Orang) }\end{array}$ & $\begin{array}{c}\mathbf{W}_{\mathbf{s}} \\
\text { (Menit) }\end{array}$ & $\begin{array}{c}\mathbf{L}_{\mathbf{q}} \\
\text { (Orang) }\end{array}$ & $\begin{array}{c}\mathbf{W}_{\mathbf{q}} \\
\text { (Menit) }\end{array}$ & $\mathbf{P}(\boldsymbol{\%})$ & $\mathbf{P}_{\mathbf{0}}(\boldsymbol{\%})$ & $\boldsymbol{P}_{\boldsymbol{n}>\boldsymbol{k}}$ \\
\hline $\mathrm{M} / \mathrm{M} / 1$ & 4,5 & 0,5 & 46,29 & 5,15 & $82 \%$ & $58 \%$ & 0,67 \\
\hline $\mathrm{M} / \mathrm{M} / \mathrm{S}$ & 0,64 & 0,08 & 0,02 & 0,0018 & $32 \%$ & $54 \%$ & - \\
\hline
\end{tabular}

Sumber: Dinas Kependudukan dan Pencatatan Sipil Kabupaten Sigi (Diolah Kembali)

Dengan melihat hasil pada Tabel 2, dapat dilihat bahwa tingkat kesibukan atau utilitas dari masingmasing model antrian sangat jauh berbeda, penggunaan satu jalur antrian tingkat utilitas atau tingkat kesibukan $82 \%$ sangatlah tidak optimal atau bisa dikatakan sangat sibuk, dan pada penggunaan 2 jalur antrian sangatlah optimal dengan melihat tingkat kesibukan yang menurun dari 0,82 atau $82 \%$ menjadi 0,32 atau $32 \%$. Dengan menurunnya tingkat kesibukan loket dapat meningkatkan tingkat nganggur loket dan akan penambahan biaya operasional kantor. Oleh karena itu perlu di adakan perhitungan kinerja rata-rata dari masing-masing tahap pelayanan. 
Tabel 3

Hasil Kinerja Rata-Rata Sistem Antrian Loket Pembuatan Kartu Tanda Penduduk (KTP) Pada Masing-Masing Tahap Pelayanan

\begin{tabular}{|c|c|c|c|c|c|c|c|}
\hline $\begin{array}{c}\text { Tahap } \\
\text { Pelayanan }\end{array}$ & $\begin{array}{c}\mathbf{L}_{\mathbf{s}} \\
\text { (Orang) }\end{array}$ & $\begin{array}{c}\mathbf{W}_{\mathbf{s}} \\
\text { (Menit) }\end{array}$ & $\begin{array}{c}\mathbf{L}_{\mathbf{q}} \\
\text { (Orang) }\end{array}$ & $\begin{array}{c}\mathbf{W}_{\mathbf{q}} \\
\text { (Menit) }\end{array}$ & $\mathbf{P}(\boldsymbol{\%})$ & $\mathbf{P}_{\mathbf{0}}(\boldsymbol{\%})$ & $\boldsymbol{P}_{\boldsymbol{n} \text { (k }}$ \\
\hline I & -9 & -1 & -10.13 & -1.13 & $1.13 \%$ & $-0.13 \%$ & 1.27 \\
\hline II & 9 & 1 & 8.1 & 0.9 & $0.9 \%$ & $0.1 \%$ & 0,81 \\
\hline III & $-1,5$ & $-0,17$ & -162 & -18 & $3 \%$ & $-2 \%$ & 9 \\
\hline
\end{tabular}

Sumber: Dinas Kependudukan dan Pencatatan Sipil Kabupaten Sigi (Diolah Kembali)

Berdasarkan Tabel 3 di atas, dapat dilihat bahwa dari ketiga tahap pelayanan di atas pelayanan yang sangat tinggi tingkat kesibukannya adalah pada tahap pelayanan I (pendataan) yaitu sebesar 1,13 atau $113 \%$, pada tahap pelayanan II (perekaman) yaitu 0,9 atau $90 \%$ dan pada tahap pelayanan III (pencetakan) yaitu 3 atau 300\% maka sangat perlu di adakan penambahan sistem atau penambahan fasilitas pada ketiga tahap pelayanan tersebut agar dapat mengoptimalkan sistem pelayanan pada pembuatan Kartu Tanda Penduduk (KTP).

Tabel 4

Hasil Kinerja Rata-Rata Sistem Antrian Loket Pembuatan Kartu Tanda Penduduk (KTP) dengan Penambahan Loket Pada Setiap Tahapnya

\begin{tabular}{|c|c|c|c|c|c|c|}
\hline $\begin{array}{c}\text { Tahap } \\
\text { Pelayanan }\end{array}$ & $\begin{array}{c}\mathbf{P}_{\mathbf{0}} \\
(\boldsymbol{\%})\end{array}$ & $\mathbf{P}(\%)$ & $\begin{array}{c}\mathbf{L}_{\mathbf{s}} \\
(\text { Orang) }\end{array}$ & $\begin{array}{c}\mathbf{W}_{\mathbf{s}} \\
(\text { Menit })\end{array}$ & $\begin{array}{c}\mathbf{L}_{\mathbf{q}} \\
(\text { Orang) }\end{array}$ & $\begin{array}{c}\mathbf{W}_{\mathbf{q}} \\
(\text { Menit })\end{array}$ \\
\hline I & $\mathbf{0 , 2 8 \%}$ & $\mathbf{0 , 5 7 \%}$ & $\mathbf{1 , 2 2}$ & $\mathbf{0 , 1 4}$ & $\mathbf{0 , 0 9}$ & $\mathbf{0 , 0 0 9 7}$ \\
\hline II & $\mathbf{0 , 3 8 \%}$ & $\mathbf{0 , 4 5 \%}$ & $\mathbf{0 , 9 4}$ & $\mathbf{0 , 1 1}$ & $\mathbf{0 , 0 4}$ & $\mathbf{0 , 0 0 5}$ \\
\hline III & $\mathbf{0 . 0 3 8 \%}$ & $\mathbf{0 , 7 5 \%}$ & $\mathbf{4 , 5 3}$ & $\mathbf{0 , 5 1}$ & $\mathbf{1 , 5 3}$ & $\mathbf{0 , 1 7}$ \\
\hline
\end{tabular}

Sumber: Dinas Kependudukan dan Pencatatan Sipil Kabupaten Sigi (Diolah Kembali)

Berdasarkan Tabel 4 di atas, dapat dilihat bahwa dari tahap pelayanan I (pendataan) dengan melihat rata-rata masyarakat menunggu dalam antrian hanya 0,09 atau tidak ada orang yang menunggu dalam antrian, dan tingkat kesibukan loket bisa dikatakan sudah optimal yaitu 0,57 atau 57\% dengan melakukan penambahan menjadi 2 loket pada tahap pendataan, pada tahap pelayanan II (perekaman) dilihat dari tingkat utilitas loket adalah 0,45 atau $45 \%$ dengan melakukan penambahan menjadi 2 loket, dan pada tahap pelayanan III (pencetakan) bila dilakukan penambahan menjadi 4 loket atau fasilitas pada layanan ini maka sangat berpengaruh baik terhadap proses pelayanan, jika dilihat dari tingkat utilitas pada saat dilakukan penambahan sistem tingkat kesibukan sudah optimal yaitu dari $300 \%$ menjadi $75 \%$. Dengan melakukan penambahan pada setiap tahap layanan tersebut dapat mengoptimalkan sistem pelayanan dan mempercepat proses pembuatan Kartu Tanda Penduduk (KTP).

Dalam hal mengoptimalkan pelayanan, Dinas Kependudukan dan Pencatatan Sipil Kabupaten Sigi dapat mengganti atau menerapkan model antrian Multi Channel Multi phase yaitu sistem yang mempunyai lebih dari satu jalur antrian dan beberapa fasilitas pelayanan pada setiap tahapnya, sehingga lebih dari satu masyarakat dapat dilayani pada waktu yang sama. 
sebanyak 2 jalur, sehingga untuk alur pelayanan tahap pendataan 1 lalu ke perekaman 1 dapat memasuki salah satu tahap pelayanan pencetakan yang tidak terdapat masyarakat didalamnnya untuk dilayani, begitu pula dengan alur pelayanan tahap pendataan 2. Dengan melakukan penambahan loket pada ketiga tahap layanan dapat mengoptimalkan sistem pelayanan pada kantor Dinas Kependudukan dan Pencatatan Sipil Kabupaten Sigi karena lebih dari satu masyarakat dapat dilayani pada waktu yang sama.

\section{KESIMPULAN DAN SARAN}

\section{Kesimpulan}

Berdasarkan pembahasan dan pengolahan data yang telah dikemukakan sebelumnya, penulis dapat mengambil beberapa kesimpulan sebagai berikut :

1. Sistem antrian pada loket pembuatan Kartu Tanda Penduduk (KTP) di Dinas Kependudukan dan

Pencatatan Sipil Kabupaten Sigi yang saat ini menggunakan 1 jalur antrian belum berjalan secara optimal.

2. Sistem antrian pada loket pembuatan Kartu Tanda Penduduk (KTP) di Dinas Kependudukan dan Pencatatan Sipil Kabupaten Sigi memiliki karakteristik ukuran populasi tidak terbatas, kedatangan cenderung acak dan berkelompok, panjang antrian tidak dibatasi, dan desain Single Channel Multi Phase.

\section{Saran}

Berdasarkan kesimpulan di atas maka penulis dapat memberikan saran kepada Dinas Kependudukan dan Pencatatan Sipil Kabupaten Sigi, yaitu merubah sistem antrian yang sekarang dengan sistem antrian Multi Channel Multi Phase agar dapat mengoptimalkan pelayanan dan mempercepat proses pembuatan Kartu Tanda Penduduk (KTP).

\section{REFERENSI}

Heizer, J., \& Render, B. 2008. Manajemen operasi. Jakarta: Salemba Empat.

Hilda. Saharuddin, K dan Husein Hi. Moh. Saleh. 2018. Analisis Antrian Pelayanan Nasabah Pada PT Bank Syariah Mandiri Cabang Bungku. Jurnal, Ilmu Manajemen Universitas Tadulako.

Pardede, A.M.H., Mawengkang, H., \& Situmorang, Z. 2014. Simulasi Antrian Berdatangan Berkelompok Dengan Pelayanan Weibull Oleh Banyak Server. Jurnal Teknologi Informasi Dan Komunikasi, 3(1), 1-10

Rian, 2015. Analisis Sistem Antrian di Dinas Kependudukan dan Pencatatan Sipil Kota Bandung: Studi Pada Loket Pelayanan Pencatatan dan Penerbitan Akta Kelahiran Bayi Berumur 0-60 Hari. Jurnal, Fakultas Komunikasi dan Bisnis Universitas Telkom.

Siagian, P. 1987. Penelitian operasional: Teknik dan praktek. Jakarta: Penerbit Universitas Indonesia (UI-Press).

Sugiyono., 2015. Metode Penelitian Kombinasi (Mixed Methode), Alfabeta, Bandung. 